\title{
Airflow mixing augmentation device for hot-air heating systems in modular boilers
}

\author{
Nikolay I. Kurilenko ${ }^{1}$, Pavel A. Artamonov ${ }^{1}$, Elena Yu. Kurilenko ${ }^{1}$, and Gennady Ya. \\ Mamontov $^{2, *}$ \\ ${ }^{1}$ Industrial University of Tyumen, 625001 Tomsk, Russia \\ ${ }^{2}$ National Research Tomsk Polytechnic University, 634050 Tomsk, Russia
}

\begin{abstract}
The article demonstrates the results of the theoretical research devoted to the study of air flow interaction in hot-air heating systems of automatic modular boilers involving the use of fan heaters. The work quotes the results of mathematic simulation of various density air flows that are vertical to each other.
\end{abstract}

\section{Introduction}

In recent times, a great attention has been paid to energy-saving issues in various production spheres. This article studies one of the techniques to optimize the hot-air heating system of automatic modular boilers. Air thermal conditions have a direct control over the boiler efficiency factor [1].

The use of water fan heater-based hot-air heating in automatic modular boilers is one of the efficient solutions of the air thermal conditions issue. The fan heater is set at right angle to a supply grill. An incoming stream of the cold outer air is thrown off by the hot air stream from the fan heater and is heated [2]. This heating and ventilation system (HV) compared to air handling units is characterized by lower capital and maintenance costs, a higher reliability (warm-air furnace freezing is excluded) and ease of automatic control. Despite its advantages, this system efficiency reduces together with the decrease in the outer air temperature. It is related to a higher flow velocity $(1-1.5 \mathrm{~m} / \mathrm{s})$ and a different flow density of hot and cold air streams (the cold air density can exceed the hot air density by more than $50 \%$ ).

\section{Problem statement and solution procedure}

We simulate the boiler block box room with the fan heater-based heating and ventilation system. The room dimensions are $3.0 \times 4.0 \times 8.0 \mathrm{~m}$ with coordinates $\mathrm{X}, \mathrm{Z}$ and $\mathrm{Y}$ respectively (fig.1). The cold air flows through the supply grill with a fixed-rate mass flow $G$ equal to $1.37 \mathrm{~kg} / \mathrm{s}$ and a temperature of $223 \mathrm{~K}\left(-50^{\circ} \mathrm{C}\right)$. The fan heater soaks up the inner air at a rate of $\mathrm{G}$ and this air is supplied at right angles to the inflowing air stream at $323 \mathrm{~K}$. All specified area is filled with the air whose characteristics change at the ideal gas law. We use

\footnotetext{
* Corresponding author: gmamontov@tpu.ru
} 
the finite-volume difference scheme [3] and solve the following equations [4] to determine the temperature distribution by the hole cross section that the heated air is evacuated through.

- $\quad$ equation of continuity:

$$
\frac{\partial \rho}{\partial t}+\nabla \bullet(U \rho)=0
$$

where $\rho$ - density, $\mathrm{kg} / \mathrm{m}^{3} ; t$ - time, $\mathrm{s} ; U$ - velocity vector, $\mathrm{m} / \mathrm{s}$;

- impulse law:

$$
\frac{\partial(U \rho)}{\partial t}+\nabla \bullet(U \rho \otimes U)=-\nabla p+\nabla \bullet \tau+S_{M}
$$

where $p$ - thermodynamic pressure, $\mathrm{Pa} ; S_{M}$ - volume mass source, $\mathrm{kg} / \mathrm{m}^{2} \cdot \mathrm{s}^{3} ; \tau$ - stress tensor is described by (3):

$$
\tau=\mu\left(\nabla U+(\nabla U)^{T}-\frac{2}{3} \delta \nabla \bullet U\right)
$$

where $\mu-$ dynamic coefficient of viscosity, $\mathrm{Pa} \cdot \mathrm{s} ; \delta-$ Kronecker function; $\mathrm{T}-$ temperature, $\mathrm{K}$;

- $\quad$ energy conservation law:

$$
\frac{\partial(\rho e)}{\partial t}+\nabla \bullet(\rho U e)=\nabla \bullet(\lambda T)+p \nabla \bullet U+\tau: \nabla U+S_{E}
$$

where $e$ - internal energy; $\tau: \nabla U$ - viscous dissipation; $\mathrm{S}_{\mathrm{E}}-$ volume energy source, $\mathrm{kg} / \mathrm{m} \cdot \mathrm{s}^{3}$.

The gravity differential air pressure is described by the buoyancy model based on Boussinesq thermal convection equation:

$$
\rho=\rho_{\text {Bref }}\left(1-\beta\left(T-T_{\text {Bref }}\right)\right)
$$

where $\rho_{\text {Bref }}-$ substance density at the temperature of the problem initial data, $T_{\text {Bref }}$, $\mathrm{kg} / \mathrm{m}^{3}, \mathrm{~T}$ - temperature at the reference point, $\mathrm{K}, \beta$ - coefficient of volume expansion, that can be determines as:

$$
\beta=\frac{1}{\rho} \cdot \frac{\partial \rho}{\partial T}
$$

At all geometry boundaries, we use a nonslip wall model and as a turbulence model, we take Menter's shear stress transport model [5].

The (1)-(6) equations solution is a temperature distribution by the specified geometry cross section that the heated air is evacuated through (fig.2). As the figure 2 illustrates, there is a high thermal block box height gradient (in this case it is equal to $8.4{ }^{\circ} \mathrm{C} / \mathrm{m}$ ) when the fan heater-based heating and ventilation system that operates as a hot air curtain under inflowing air low temperatures, is used and it proves the low efficiency of the heating and ventilation system under these conditions. 


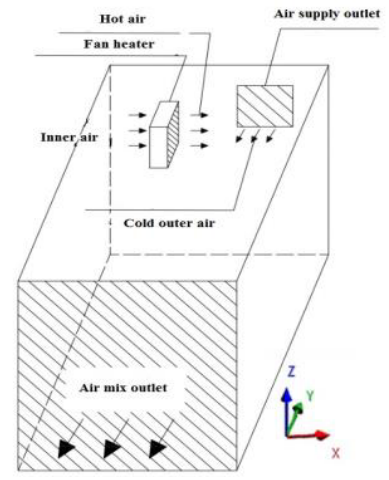

Fig. 1. Analytic model.

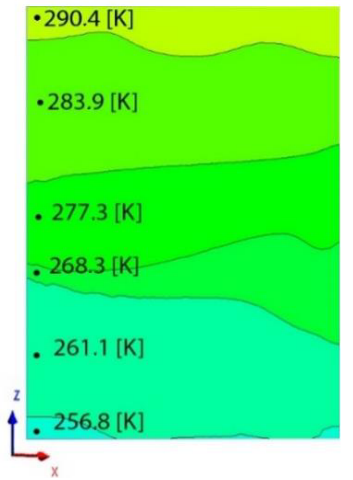

Fig. 2. Temperature field distribution at the exit area.

When the hot air from the fan heater makes contact to the cold inflowing air, there is not an overall mixing and a part of the heat goes up under gravity forces, and the cold inflowing air goes down creating a high thermal gradient. This effect can be observed in figure 3 (B). The numerical simulation result illustrates that the major part of cold and hot air flows does not mix. As it can be seen in figure $3(\mathrm{C})$, the mixing occurs only in the contact area of two jets. Despite the fan heater in service, the cold air with a temperature lower than $-30{ }^{\circ} \mathrm{C}$ descends to the room floor and drifts low over it (fig. $3 \mathrm{~B}, \mathrm{C}$ ).

Due to the high thermal gradient, we can observe the cold air flow formation over the block box room floor that can result in equipment freezing. The use of modular boilers shows that the fan heater-based heating and ventilation system can be operated without any additional changes at the outer air temperature up to $-30^{\circ} \mathrm{C}$. Under these conditions, we observe a high value of the thermal gradient, but if the supply grills are at the top of the room, there are not negative temperature streams over the floor. If the inflowing air temperature is below $30^{\circ} \mathrm{C}$, there is a need in an engineering solution that will allow to heat the cold air coming to the room through the fan heater and to decrease the thermal gradient room heightwise.

A
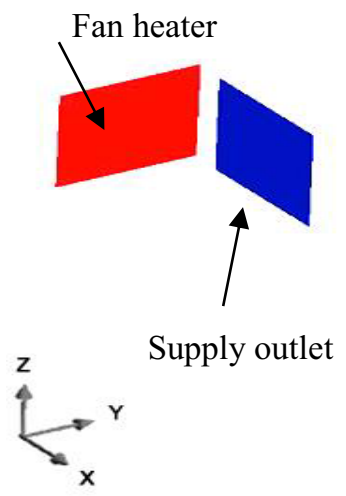

B

Isosurfaces, corresponding to the temperature of $+30^{\circ} \mathrm{C}$

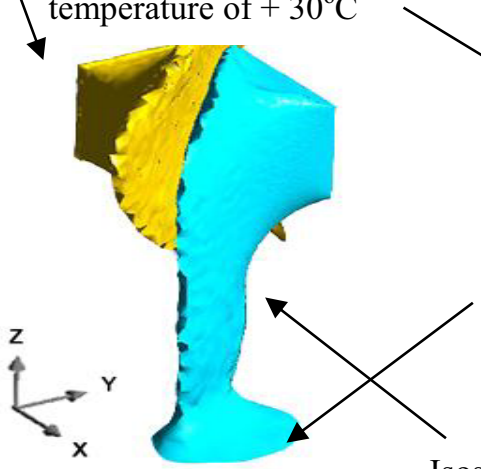

Isosurfaces, corresponding to the temperature of $-30^{\circ} \mathrm{C}$

Fig. 3. Isosurfaces, corresponding to temperatures of $+30^{\circ} \mathrm{C}$ and $-30^{\circ} \mathrm{C}$.

The energy efficiency is based on the minimization of capital costs to obtain a useful effect [6] so the optimization task of the fan heater-based heating and ventilation system 
involves the development of the device that will allow providing an efficient inflowing air heating at low capital and maintenance costs.

We have analyzed the cold and hot air streams distribution (fig.3) and have supposed that one of the ways to increase the mixing efficiency is a flow motion limitation in space.

Let us study the box that is made of a sheet metal. The box is supposed to have holes for the fan heater, the supply grill and the outlet (fig.4). This design will allow limiting the stream distribution at $\mathrm{Z}$ axis and keep the cold air from going downwards, and the hot air upwards. The outlet that is smaller than the total area of the air supply outlet and the fan heater can direct the air mixture upwards at the velocity that is two times higher than in the air supply outlet.

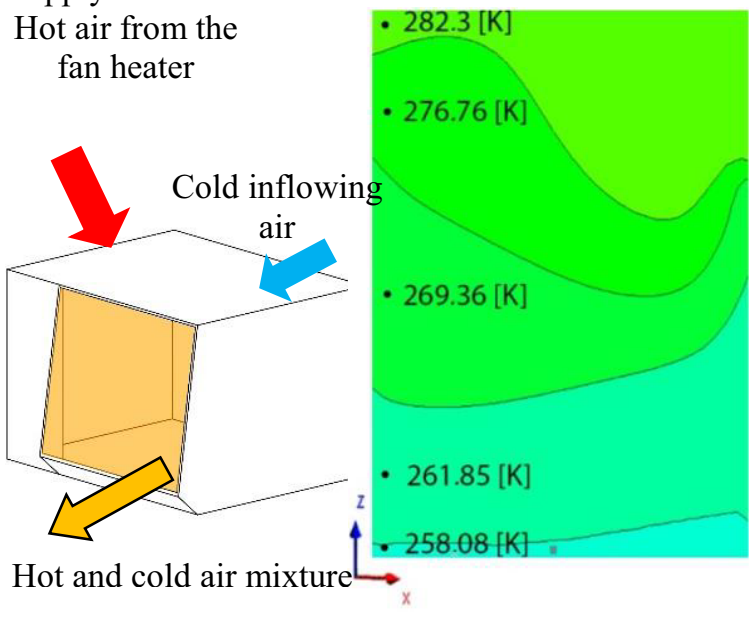

Fig. 4. General view of the space box to mix air flows.
Fig. 5. Temperature field distribution at the exit area when the mixing box is used.

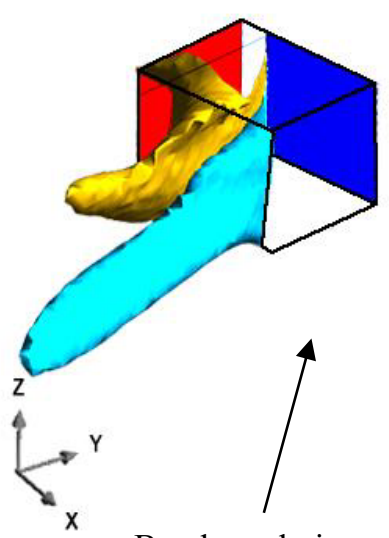

Box boundaries

Fig. 6. Isosurfaces, corresponding to temperatures of $+30^{\circ} \mathrm{C}$ and $-30^{\circ} \mathrm{C}$ when the mixing box is used.

We have carried on modeling based on the box geometry and we have had the temperature field distribution at the specified geometry exit area (fig. 5), and isosurfaces with the temperatures of $+30^{\circ} \mathrm{C}$ and $-30^{\circ} \mathrm{C}$ (fig. 6). As it can be seen from these figures, the box use decreases the thermal gradient up to $6{ }^{\circ} \mathrm{C} / \mathrm{m}$. If we take the thermal gradient as a quality criteria of the hot and cold air stream mixing, we can assume that the box use in this design allows to increase the fan heater-based heating and ventilation system efficiency by $28.6 \%$ without any maintenance cost increase. The figure 6 shows that the cold air stream with the temperature of $-30^{\circ} \mathrm{C}$ does not come to the simulated room floor.

Despite the fact that the box use has increased the mixing efficiency almost by a third, this system is not still efficient enough for heating and ventilation systems at inflowing air low temperatures. The box concept of this design has a range of disadvantages. Firstly, the cross section area is reduced, thus it increases the airflow resistance (the resistance has increased from $1 \mathrm{~Pa}$ to $14.5 \mathrm{~Pa}$ ), so the discharge characteristic of the fan heater changes. Secondly, even if the box has limited the stream distribution along Z-axis, this design has not allowed the stream mixing that gives a higher cold air stream penetration due to the speed increase. This system can cause the equipment freezing at the central part of the room.

The jet theory of G. Abramovich is studied in detail in [4], [5], [6] and [7], and these works reproduce the calculation of hot air curtains bearing in mind various factors and 
operation conditions. Based on the results of these works and concepts described in inventions No. 290154 of 23.11.1971 and No. 688786 of 30.09.1979, we have developed the space structure to enhance the cold and hot air stream mixing. The general view of this structure is presented in figure 7. The device operation is based on the flow distribution principle. The flows are divided into two zones by plates. In the first zone only the hot air moves. The second zone is characterized by the contact of the heated air and the air under heating. Thus, the total flow is divided into sandwiched layers of the hot and cold air that mix as they leave the flow separation device.

\section{Conclusion}

We have carried on the mathematic simulation with the flow separation device and have got the temperature distribution at the specified geometry exit area (fig. 8) and isosurfaces that correspond to the temperatures of $+30^{\circ} \mathrm{C}$ and $-30^{\circ} \mathrm{C}$ (fig. 9).

As it can be seen in figures 7, 8 and 9 the flow separation device provides the decrease of thermal gradient room heightwise from $8.4{ }^{\circ} \mathrm{C} / \mathrm{m}$ до $1.4{ }^{\circ} \mathrm{C} / \mathrm{m}$. The this design does not oversize the separation device, but it allows to reduce the resistance up to $7.4 \mathrm{~Pa}$ due to the cross section area extension.

Thus, the developed design helps increase the air heating system efficiency at low temperatures of the inflowing air a sixfold without any maintenance cost increase. In addition, the cold air flow jet penetration is four times lower.

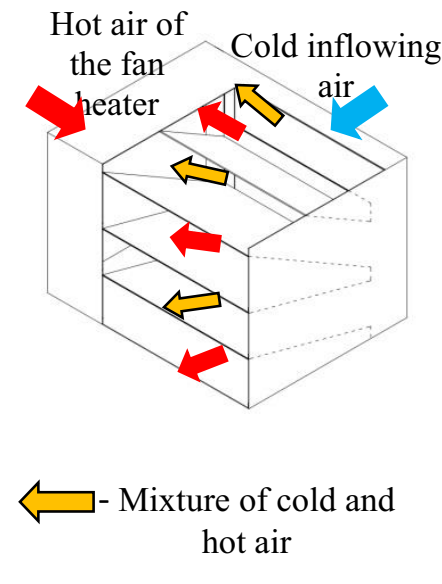

Fig. 7. General view of the flow separation device.

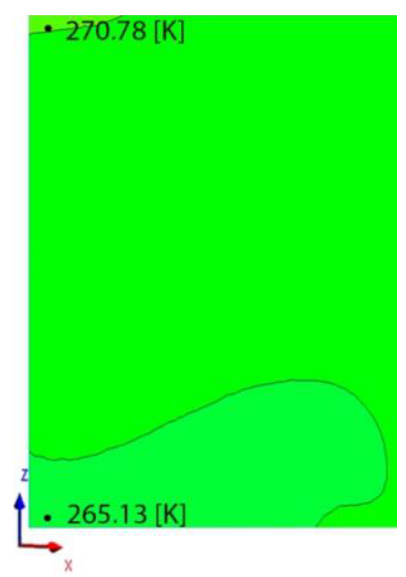

Fig. 8. Temperature field distribution at the exit area when the flow separation device is used.

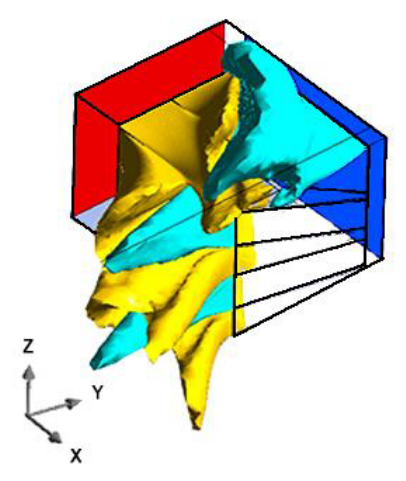

Fig. 9. Isosurfaces, that correspond to the temperatures of $+30^{\circ} \mathrm{C}$ and $-30^{\circ} \mathrm{C}$ when the flow separation device is used.

\section{References}

1. G.N. Abramovitch, Theory of turbulent jets. Reprint version of 1960. //ECOLIT, 720 (2011)

2. N.I. Kurilemko, Privolzhsky academic journal 2, 116 (2014) 
3. N.I. Kurilenko, L.Yu. Mikhaylova, P.A. Artamonov, Bulletin of TSUAB 4. 171 (2012)

4. A.B. Kaplun, E.M. Morosov, M.A. Olferieva, Editorial UMSS, 272 (2003)

5. ANSYS HELP / CFX / Modeling Guide http://orange.engr.ucdavis.edu/ Documentation12.0/120/CFX/xmod.pdf

6. The Menter Shear Stress Transport Turbulence Model/ Turbulence Modeling Resource / - NASA. Langley Research Center - http://turbmodels.larc.nasa.gov/ sst.html

7. D. Macklin, A. Yashina, Energy bulletin 4, 43 (2009)

8. V.N. Bogoslovsky, V.I. Novozhilov, B.D. Simakov, V.P. Titov, Heating and ventilation (Stroyizdat, Moscow, 1976)

9. V.V. Baturin, Fundamentals of industrial ventilation, Fourth edition (Profizdat, Moscow, 1990)

10. V.N. Taliev, Ventilation aerodynamics, Manual for graduate students (Stroyizdat, Moscow, 1979)

11. G.N. Abramovitch, Theory of turbulent jets. Reprint version of 1960 (ECOLIT, Chicago, 2011) 